\title{
Experimental Study on the Influence of Sulfate Reducing Bacteria on the Metallic Corrosion Behavior under Disbonded Coating
}

\author{
Qingmiao Ding, ${ }^{1}$ Liping Fang, ${ }^{2}$ Yanyu Cui, ${ }^{1}$ and Yujun Wang ${ }^{1}$ \\ ${ }^{1}$ Airport School, Civil Aviation University of China, Tianjin, China \\ ${ }^{2}$ Guangxi Colleges and Universities Key Laboratory of Beibu Gulf Oil and Natural Gas Resource Effective Utilization, \\ Qinzhou University, Qinzhou 535011, China
}

Correspondence should be addressed to Qingmiao Ding; qmding@cauc.edu.cn

Received 20 April 2017; Accepted 18 July 2017; Published 23 October 2017

Academic Editor: Flavio Deflorian

Copyright (C) 2017 Qingmiao Ding et al. This is an open access article distributed under the Creative Commons Attribution License, which permits unrestricted use, distribution, and reproduction in any medium, provided the original work is properly cited.

\begin{abstract}
A rectangle disbonded coating simulation device was used to research the effect of sulfate reducing bacteria (SRB) on the metallic corrosion behavior under disbonded coating by the electrochemical method. The results showed that the metal self-corrosion potential at the same test point had little change in the initial experiment stage, whether the solution was without or with SRB. The potential amplitude in the solution with SRB was larger than that without SRB in the later corrosion period. The corrosion current density of the metal at the same test point increased gradually over time in the solution with or without SRB, and SRB could accelerate the corrosion of the metal in the disbonded crevice. The metal self-corrosion potential in the crevice had little change in the SRB solution environment after adding the fungicide, but the corrosion current density decreased significantly. That meant the growth and reproduction of SRB were inhibited after adding the fungicide, so the metal corrosion rate slowed down. Among the three kinds of solution environment, increasing the coating disbonded thickness could accelerate the corrosion of the metal in the crevice, and it was the largest in the solution with SRB.
\end{abstract}

\section{Introduction}

With the rapid development of buried pipeline construction, more and more attention had been paid to the problem of pipeline corrosion [1-5]. The buried pipelines were arranged in a crisscross pattern, and this would cause fire and explosion once they start to corrode and leak; that would threaten the personal safety and cause environmental pollution. The anticorrosion coating of the buried pipeline often had disbonded area with broken open holiday due to the mechanical damage, aging and degradation, cathodic disbondment, and other reasons in the process of pipeline installation and using [6-8]. It formed the special corrosive environment between the anticorrosion coating and pipeline surface, and the moisture, the soluble ion like $\mathrm{CO}_{2}$ and $\mathrm{O}_{2}$ and other corrosive media in the soil got into the disbonded area through the holiday; that caused the corrosion of the metal under the disbonded coating [9-11]. A large number of studies showed that the content of moisture and bacteria in the backfill soil was more than that in the original uncultivated soil, and that would cause microbial corrosion (MIC) due to microbial activity under disbonded coating [12-14]. The sulfate reducing bacteria (SRB) as a kind of microorganism widely existed in soil, sea, river water, underground pipeline, oil gas well, and so on, and they made the pipeline more prone to perforation in the solution with SRB. So the metal corrosion caused by SRB in recent years was taking more and more attention; there have been massive researches about SRB corrosion on emergence [15-18] and some reporting about metal corrosion under disbanded coating $[19,20]$, but up to now, there was no study on the SRB corrosion behavior under disbonded coating. Therefore, we built a rectangle crevice device for the metal corrosion under disbonded coatings and researched the regularity of SRB corrosion on 


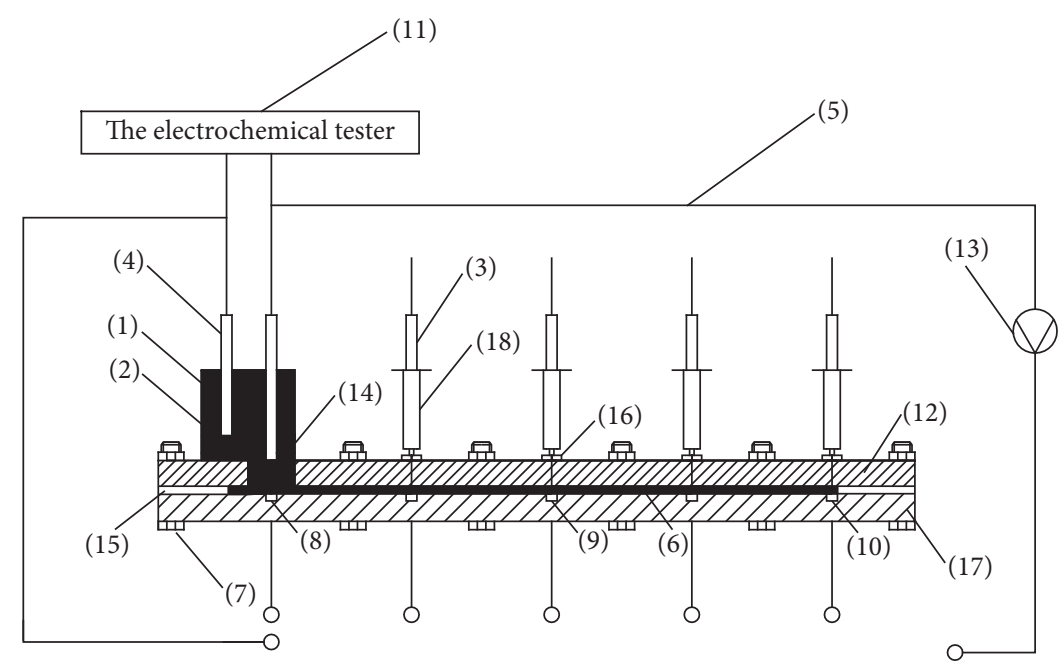

FIgURE 1: The experimental device. (1) Organic glass box; (2) soil simulated solution; (3) the saturated calomel electrode with salt-bridge; (4) auxiliary anode; (5) wire; (6) gap space; (7) bolt; (8) working electrode at test point 1; (9) working electrode at test point 2; (10) working electrode at test point 3; (11) electrochemical tester; (12) organic glass plate; (13) voltmeter; (14) the point of coating damage; (15) the spacer; (16) rubber plug; (17) epoxy resin board; (18) needle tubing.

the metal under disbonded coatings by the electrochemical method. It is meaningful to the safe operation and long-term service of the pipeline in the soil environment.

\section{Experiment Content}

2.1. Experimental Device. Experiment device was shown in Figure 1; we use the epoxy resin plate and organic glass plate of $30 \mathrm{~cm} \times 10 \mathrm{~cm} \times 0.5 \mathrm{~cm}$ while simulating the situation of coating disbonded, also we put a gasket of $0.5 \mathrm{~mm}$ thickness between them for regulating the thickness of simulation stripping gap. We drill a round hole of $1 \mathrm{~cm}$ diameter as point 1 to simulate coating damage point on organic glass plate near the end of $7 \mathrm{~cm}$ and drill the round holes of $0.5 \mathrm{~cm}$ diameter at $80 \mathrm{~mm}$ and $160 \mathrm{~mm}$ from the damaged point, respectively, as the electrochemical parameters test point 2 and point 3. We set an organic glass box on point 1 of the organic glass plate to contain simulated soil solution and set the working electrodes, respectively, in the epoxy resin plate with points $1 \sim 3$ in the organic glass plate while simulating the pipeline metal under the disbonded coating.

2.2. The Experimental Material. The working electrode was made from X80 steel, and its chemical composition was shown in Table 1. The sample was made of the small cylindrical specimens, $10 \mathrm{~mm}$ diameter, and the electrode surface was polished successively with 60\# 2000\# sandpaper by MP-2 metallographic sample pregrinding machine until the metal surface was smooth and there were no obvious signs; then we washed away the surface oil with acetone and washed away the surface residues water and acetone with anhydrous ethanol and then put it into the drying box for use. The reference electrode was saturated calomel electrode (in this paper, if there were no special instructions, the potential was defined relatively to the saturated calomel reference electrode). The auxiliary electrode was platinum electrode.
The composition of the solution was as follows: $0.1712 \mathrm{~g}$ $\mathrm{Na}_{2} \mathrm{SO}_{4}, 0.1600 \mathrm{~g} \mathrm{Na}_{2} \mathrm{CO}_{3}, 0.0865 \mathrm{~g} \mathrm{NaHCO}_{3} 0.5125 \mathrm{~g} \mathrm{NaCl}$, and $1 \mathrm{~L}$ distilled water.

SRB was selected as the experimental bacterial strain. The medium composition of SRB strains was as follows: $0.5 \mathrm{~g}$ $\mathrm{KH}_{2} \mathrm{PO}_{4}, 0.06 \mathrm{~g} \mathrm{CaCl}_{2}, 0.06 \mathrm{~g} \mathrm{MgSO}_{4} \cdot 7 \mathrm{H}_{2} \mathrm{O}, 1.0 \mathrm{~g} \mathrm{NH}_{4} \mathrm{Cl}$, $0.3 \mathrm{~g} \mathrm{C}_{6} \mathrm{H}_{5} \mathrm{Na}_{3} \mathrm{O}_{7} \cdot 2 \mathrm{H}_{2} \mathrm{O}, 6.0 \mathrm{~g} \mathrm{CH}_{3} \mathrm{CH}(\mathrm{OH}) \mathrm{COONa}$, $1.0 \mathrm{~g}$ yeast extract powder, and $1 \mathrm{~L}$ distilled water. We put the readyprepared medium in the high temperature steam sterilization pot $\left(120^{\circ} \mathrm{C}\right)$ to sterilize $30 \mathrm{~min}$ before starting the experiment. We use glutaraldehyde $\left(\mathrm{C}_{5} \mathrm{H}_{8} \mathrm{O}_{2}\right)$ as the fungicide.

2.3. The Experiment Content. The rectangle crevice device was used to study the SRB corrosion behavior of the metal in the crevice under the disbonded thickness of $0.5 \mathrm{~mm}$ and $1.0 \mathrm{~mm}$, respectively. The experimental period was 14 days, and we test the electrochemical impedance spectroscopy (EIS) and polarization curves by the electrochemical workstation in the test period.

\section{The Experimental Results and Discussion}

3.1. The SRB Corrosion Behavior of the Metal in Different Solution Environments. As shown in Figure 2 and Table 2, the self-corrosion potential of the metal in the crevice at the same test point had a little change in the solution without or with SRB in the initial stage when the disbonded thickness was $0.5 \mathrm{~mm}$, and it tended to be stable. But there was obvious potential amplitude of self-corrosion potential in the later stage, and the amplitude affected with SRB was much larger than that without SRB. The self-corrosion potential of the metal without SRB was more negative than that with SRB. With the extension of time, the corrosion current density of the metal in the crevice gradually increased at the same test point in two solutions, and the corrosion current density of the metal affected with SRB was significantly greater than that 

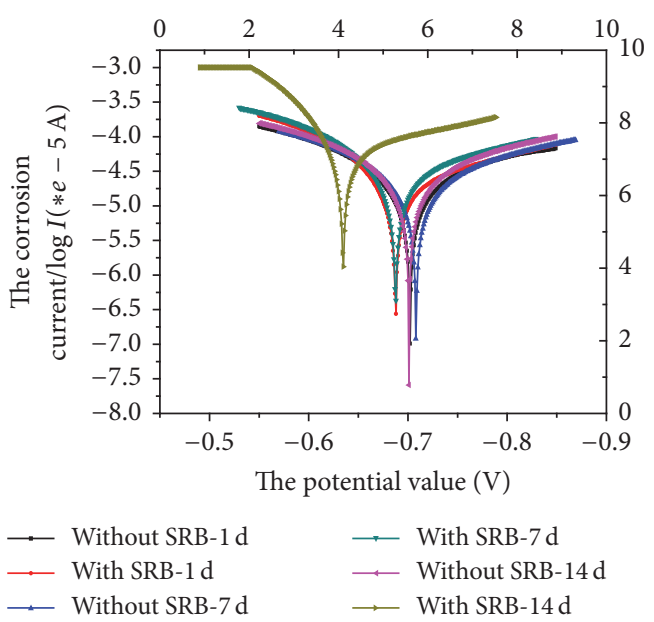

(a) The polarization curves of the damaged point in different time
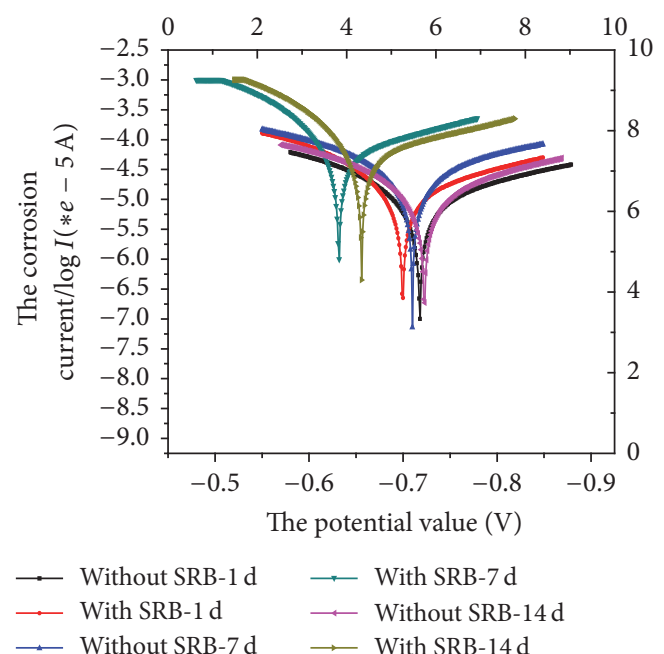

(c) The polarization curves of the point in the $160 \mathrm{~mm}$ stripping depth
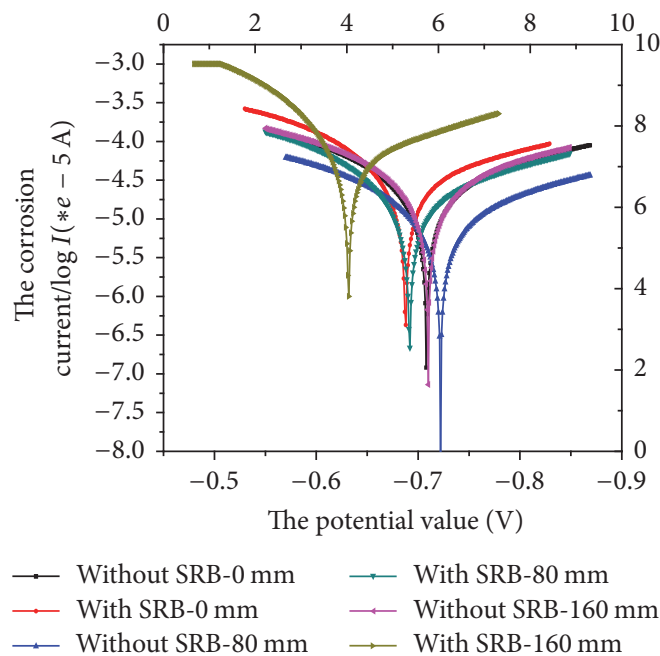

(e) The polarization curves of each point in the seventh experiment day
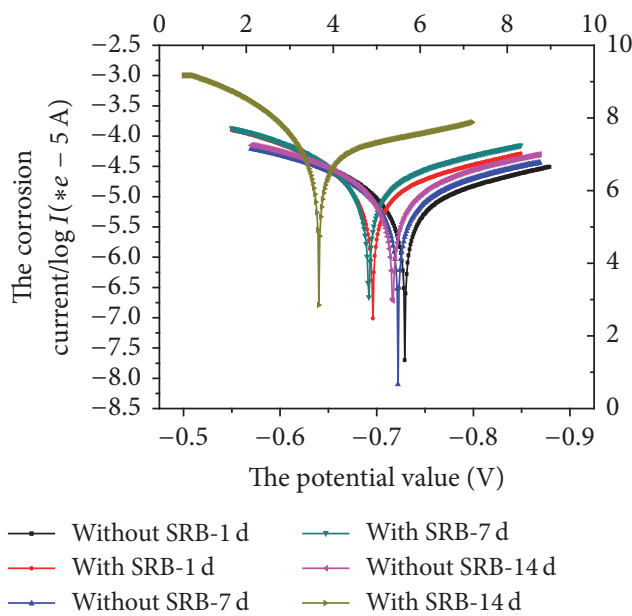

(b) The polarization curves of the point in the $80 \mathrm{~mm}$ stripping depth
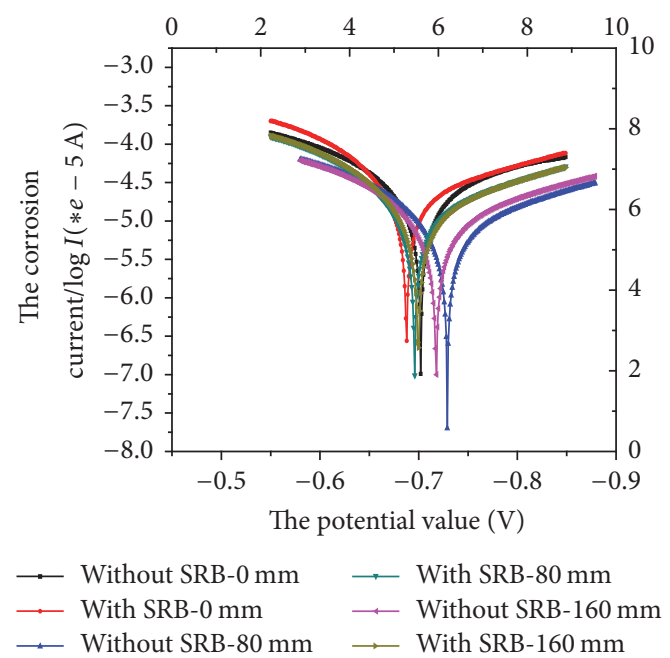

(d) The polarization curves of each point in the first experiment day

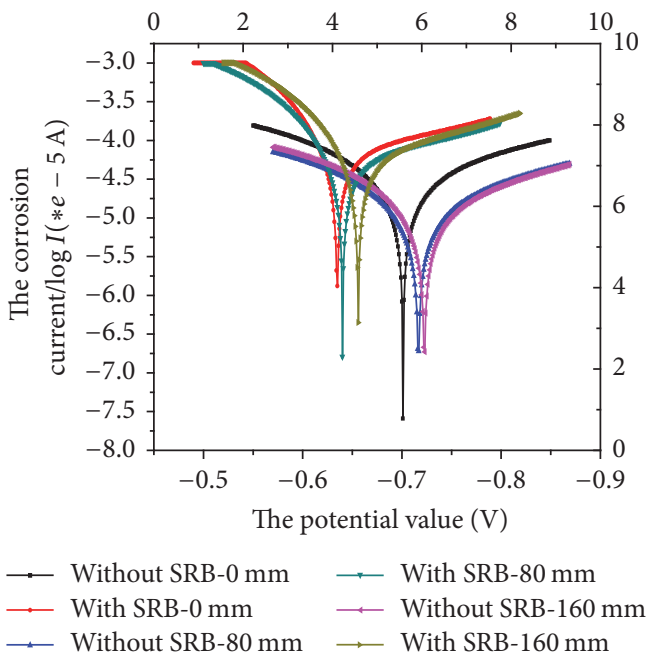

(f) The polarization curves of each point in the fourteenth experiment day

FIGURE 2: The polarization curves of the metal; the influence on the metal corrosion process with or without SRB. 
TABLE 1: The chemical composition of X80 steel (\%).

\begin{tabular}{lcccccccccccc}
\hline $\mathrm{C}$ & $\mathrm{Si}$ & $\mathrm{Mn}$ & $\mathrm{Cr}$ & $\mathrm{Mo}$ & $\mathrm{Ni}$ & $\mathrm{Al}$ & $\mathrm{Cu}$ & $\mathrm{Nb}$ & $\mathrm{Ti}$ & $\mathrm{Pb}$ & $\mathrm{Fe}$ \\
\hline 0.042 & 0.189 & 1.560 & 0.028 & 0.243 & 0.230 & 0.034 & 0.153 & 0.060 & 0.019 & 0.005 & 97.464 \\
\hline
\end{tabular}

TABLE 2: The electrochemical parameters.

\begin{tabular}{|c|c|c|c|c|c|}
\hline Simulated solution & $\begin{array}{l}\text { Experiment } \\
\text { time }\end{array}$ & $\begin{array}{c}\text { Stripping } \\
\text { depths } / \mathrm{mm}\end{array}$ & $\begin{array}{c}\text { The corrosion current } \\
\text { density } / \mu \mathrm{A} / \mathrm{cm}^{2}\end{array}$ & $\begin{array}{l}\text { The self-corrosion } \\
\text { potential/mV }\end{array}$ & $\begin{array}{c}\text { The ratio of anode Tafe } \\
\text { slope and cathode Tafel } \\
\text { slope }\end{array}$ \\
\hline \multirow{9}{*}{$\begin{array}{l}\text { Soil simulated } \\
\text { solution } \\
(\text { No. 1) }\end{array}$} & \multirow{3}{*}{$1 \mathrm{~d}$} & 0 & 23.1029 & -702 & 1.7328 \\
\hline & & 80 & 19.2514 & -722 & 1.6538 \\
\hline & & 160 & 11.5943 & -718 & 1.5963 \\
\hline & \multirow{3}{*}{$7 \mathrm{~d}$} & 0 & 43.7829 & -708 & 1.5726 \\
\hline & & 80 & 30.3086 & -722 & 1.5250 \\
\hline & & 160 & 26.0457 & -725 & 1.4844 \\
\hline & \multirow{3}{*}{$14 \mathrm{~d}$} & 0 & 45.2457 & -701 & 1.4111 \\
\hline & & 80 & 32.3429 & -717 & 1.4049 \\
\hline & & 160 & 27.7543 & -723 & 1.4831 \\
\hline \multirow{9}{*}{$\begin{array}{l}\text { Soil simulated } \\
\text { solution }+ \\
\text { SRB } \\
(\text { No. } 2)\end{array}$} & \multirow{3}{*}{$1 \mathrm{~d}$} & 0 & 25.8171 & -688 & 1.8134 \\
\hline & & 80 & 20.2457 & -696 & 1.6897 \\
\hline & & 160 & 19.5143 & -700 & 1.6727 \\
\hline & \multirow{3}{*}{$7 \mathrm{~d}$} & 0 & 30.9143 & -688 & 1.7509 \\
\hline & & 80 & 28.4971 & -692 & 1.7250 \\
\hline & & 160 & 21.7143 & -695 & 1.6395 \\
\hline & \multirow{3}{*}{$14 \mathrm{~d}$} & 0 & 78.5143 & -675 & 1.7515 \\
\hline & & 80 & 87.6457 & -680 & 1.2216 \\
\hline & & 160 & 95.4914 & -676 & 1.0870 \\
\hline \multirow{9}{*}{$\begin{array}{l}\text { Soil simulated } \\
\text { solution }+ \\
\text { SRB }+ \\
\text { fungicide } \\
\text { (No. 3) }\end{array}$} & \multirow{3}{*}{$1 \mathrm{~d}$} & 0 & 16.3886 & -694 & 1.9859 \\
\hline & & 80 & 19.0400 & -692 & 1.4779 \\
\hline & & 160 & 21.2457 & -696 & 1.3274 \\
\hline & \multirow{3}{*}{$7 \mathrm{~d}$} & 0 & 32.4343 & -698 & 1.6243 \\
\hline & & 80 & 40.1143 & -732 & 1.4063 \\
\hline & & 160 & 43.4286 & -691 & 1.4588 \\
\hline & \multirow{3}{*}{$14 \mathrm{~d}$} & 0 & 45.6114 & -684 & 1.4157 \\
\hline & & 80 & 58.8800 & -689 & 1.4475 \\
\hline & & 160 & 64.1714 & -684 & 1.4206 \\
\hline
\end{tabular}

without SRB; that meant SRB could accelerate the corrosion rate of the metal in the crevice. The amplification of the corrosion current density in the initial stage was less than that in the later stage in the solution environment with SRB. This was because the metal surface in the crevice would generate a complete microbial membrane in the solution with SRB in the initial stage of corrosion, and it provided protection for the metal in the crevice and inhibited the corrosion. But as time goes on, the corrosive material produced by SRB metabolism damaged the microbial membrane and made it rupture and fall off. At the same time, the depolarization role of SRB was gradually weakened; that made the corrosion rate of the metal in the crevice speed up. In a word, the corrosion current density of the metal in the crevice still gradually increased in the solution with SRB. At the same experimental time, the self-corrosion potential of the metal in the crevice had negative trend whether the solution is with or without SRB as the deep crack extension. The corrosion current density decreased with the increase of the stripping depths in the simulated solution without SRB. But for the solution with SRB, the corrosion current density decreased with the increase of the stripping depths in the initial stage and midstage and increased with the increase of the stripping depths in the later stage of the experiment. In addition, because the ratio of anode Tafel slope and cathode Tafel slope was bigger than 1 , we could see that when the disbonded thickness was $0.5 \mathrm{~mm}$, the control factor was anode control.

As shown in Figure 3 and Table 2, when the disbonded thickness was $0.5 \mathrm{~mm}$, the simulated solution with SRB was numbered as No. 2 and the simulated solution with SRB and fungicide was numbered as No. 3. In the No. 3 solution, the self-corrosion potential did not change much compared with 


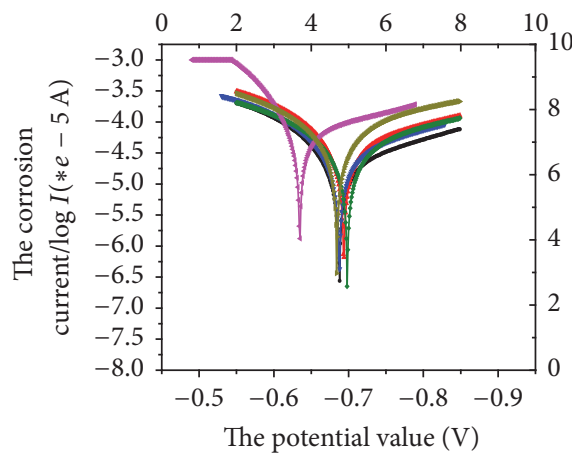

$\begin{array}{rr}\longrightarrow \text { With SRB-1 d } & \longrightarrow \text { With SRB and } \\ \longrightarrow \text { With SRB and } & \text { antiseptic-7 d } \\ \text { antiseptic-1 d } & \longrightarrow \text { With SRB-14 d } \\ \longrightarrow \text { With SRB-7d } & \longrightarrow \text { With SRB and } \\ & \text { antiseptic-14d }\end{array}$

(a) The polarization curves of the damaged point in different time
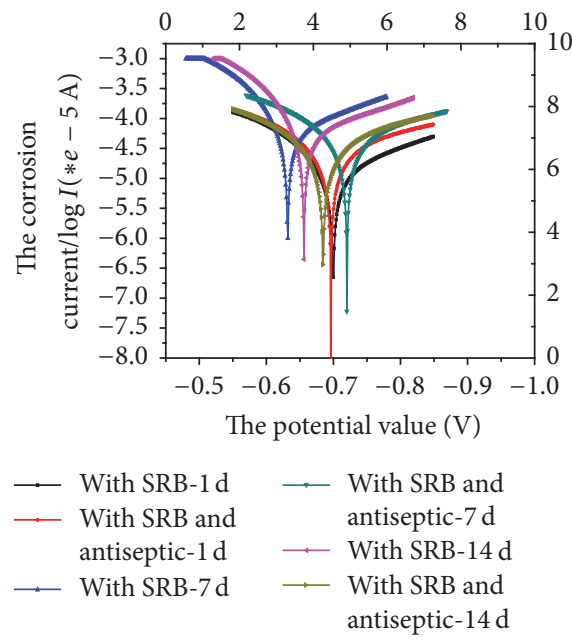

(c) The polarization curves of the point in the $160 \mathrm{~mm}$ stripping depth
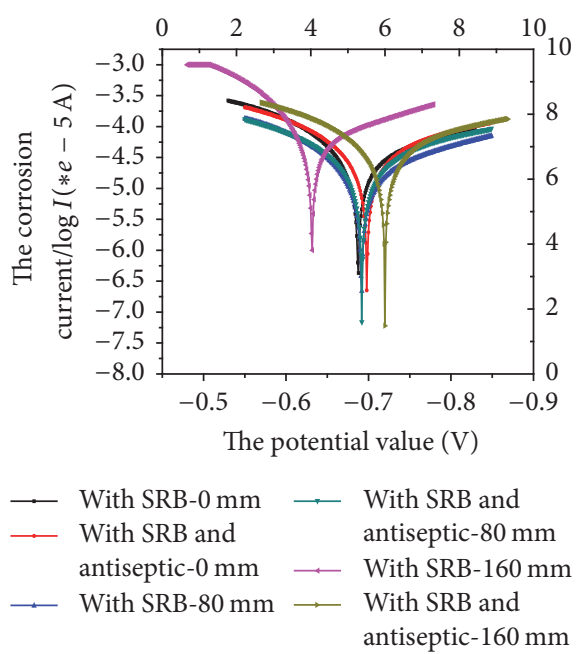

(e) The polarization curves of each point in the seventh experiment day
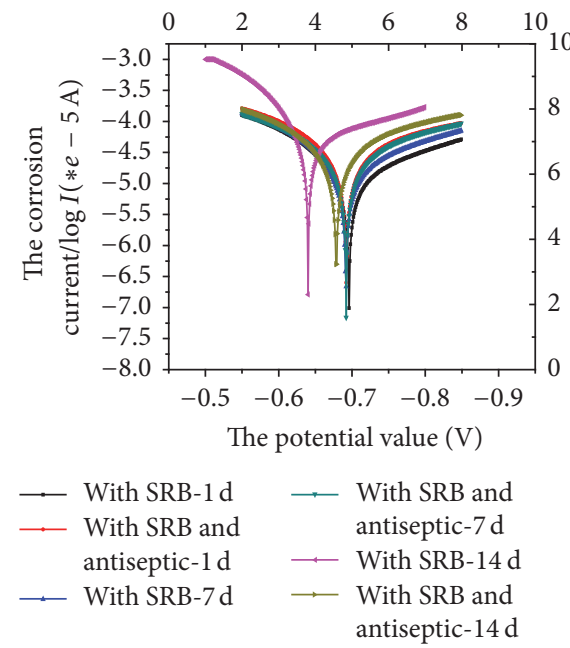

(b) The polarization curves of the point in the $80 \mathrm{~mm}$ stripping depth
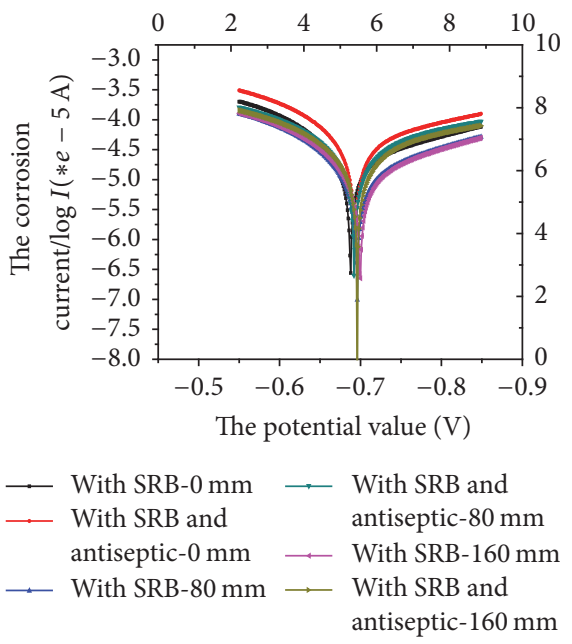

(d) The polarization curves of each point in the first experiment day
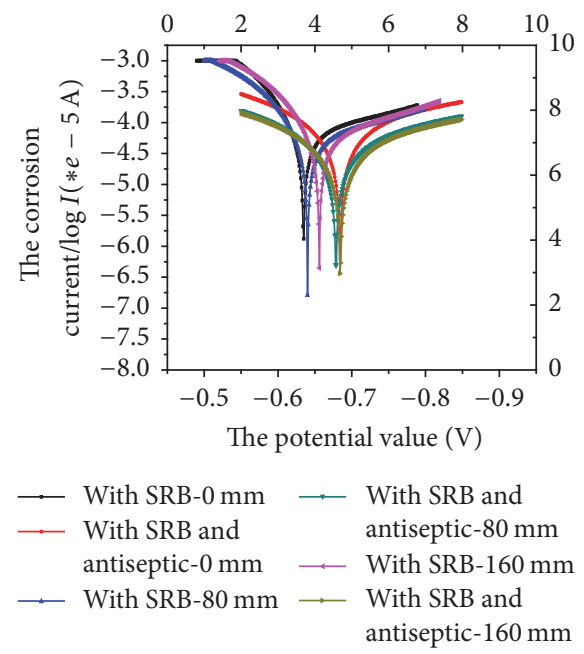

(f) The polarization curves of each point in the fourteenth experiment day

FIGURE 3: The polarization curves of the influence on the metal corrosion process with or without fungicide. 
TABLE 3: The polarization resistance under the disbonded coatings in different solution environment in the seventh experiment day/ $\Omega$.

\begin{tabular}{lccc}
\hline Simulated solution & $\begin{array}{c}\text { At the damage } \\
\text { point/mm }\end{array}$ & $\begin{array}{c}\text { At the point of } 80 \mathrm{~mm} \\
\text { stripping depth/mm }\end{array}$ & $\begin{array}{c}\text { At the point of } 160 \mathrm{~mm} \\
\text { stripping depth/mm }\end{array}$ \\
\hline $\begin{array}{l}\text { Soil simulated solution } \\
\text { Soil simulated solution + SRB }\end{array}$ & 1426.4 & 3246.3 & 3231.6 \\
$\begin{array}{l}\text { Soil simulated solution + SRB + } \\
\text { Fungicide }\end{array}$ & 955.1 & 1632.7 & 1803.1 \\
\hline
\end{tabular}

that in the No. 2 solution, but the corrosion current density significantly decreased. That meant the growth and reproduction of SRB would be inhibited after adding the fungicide and then slowed down the corrosion rate of the metal in the crevice. As the experiment time goes on, the self-corrosion potential at the same test point shifted toward negative before shifting toward positive, and the corrosion current density increased. This was because fungicide, although inhibiting the growth and reproduction of SRB, meanwhile damaged the integrity of metal surface microbiofilm and made the microbial film protection reduce, so the corrosion speed was still very fast. At the same test time, the self-corrosion potential did not change much with the increase of the stripping depths, but the corrosion current density increased; that was different from the solution only with SRB. In addition, we also could see that when the disbonded thickness was $0.5 \mathrm{~mm}$, the control factor of the corrosion in No. 3 solution was anode control in the crevice at different test point. During the whole experimental period, the change of this ratio presented the irregularity obviously; it was indicated that the motion of charged particles in the SRB solution was irregular after adding the fungicide, and the speed change was larger than before, so the conversion trend of anode control in the whole corrosion process was not obvious.

In order to accurately analyze the electrochemical impedance spectroscopy which was shown in Figure 4, the electrochemical impedance spectroscopy under different conditions was fitted through ZSimpWin software in this article. We use electrochemical equivalent circuit $\mathrm{C}(\mathrm{CR}(\mathrm{CR}))$ comprised of resistance $R$ and capacitance $C$ to represent the electrode process. The equivalent circuit diagram was shown in Figure 5.

$R_{s}$ was the solution resistance between the reference electrode and the working electrode in the crevice. $C_{f}$ was the capacitor of adsorption film formed on the corrosion metal surface. $R_{f}$ was the adsorption film resistance formed on corrosion metal surface due to the microbial attachment. $C_{d}$ was the double layer capacitance between the metal surface and the electrolyte solution. $R_{p}$ was the polarization resistance; it was associated with Faraday process and anodic reaction; thus it could reflect the corrosion well, so we would use $R_{p}$ to characterize the corrosion rate.

As shown in Figure 5, when the disbonded thickness was $0.5 \mathrm{~mm}$, the EIS of every point in the crevice in different simulated solution environment in the seventh experiment day was composed of single high-frequency capacitance and single low-frequency capacitance. The high-frequency section corresponded to the impedance signal of the corrosion product, and low-frequency section was the corrosion reaction of metal substrate. At the same stripping depths, the capacitance arc radius of the metal in solution No. 2 was the minimum, and the capacitance in solution No. 3 came second; the capacitance of the solution without SRB was the maximum. That meant the corrosion resistance of the metal under the disbonded coating in the solution with SRB was the worst, and the corrosion was the most serious. In the solution environment with SRB, the fungicide is added, the corrosion resistance of the metal under the disbonded coating was enhanced, but the corrosion was still very serious, and the capacitance arc radius was far less than that in the solution without SRB. In addition, according to the polarization resistance of various points in the crevice in different solution environment from Table 3, we could see that the polarization resistance of the metal in the crevice in the solution with SRB was the minimum, the solution with SRB and the fungicide added came second, and they were far less than that without $\mathrm{SRB}$. Therefore, the presence of SRB in the solution would reduce the resistance of the metal corrosion process in the disbonded crevice, which meant that SRB could accelerate the corrosion rate of the metal in the disbonded crevice. The results above were consistent with the conclusions obtained by the method of polarization curves analysis.

\subsection{The Effect of SRB on Corrosion Behavior of the Metal} under Different Disbonded Thickness. According to the electrochemical parameters in Table 4, in the above three kinds of simulated solution, with the increase of the coating disbonded thickness, the self-corrosion potential of the metal in the crevice shifted negatively and the corrosion current density increased obviously. As shown in Figure 6, when the coating disbonded thickness increased in the simulated solution without SRB, the crevice space became larger, and the dissolved oxygen content increased, and that accelerated the corrosion rate of the metal in the crevice. At the same experiment time, the increase amplitude of the metal corrosion current density in the crevice at the distance of $160 \mathrm{~mm}$ was significantly higher than that of $80 \mathrm{~mm}$ and that at damaged point; that meant the crevice thickness increased, of the metal which at the longer distance in the crevice had also been supplemental oxygen. In the simulated solution with SRB, as shown in Figure 7, increasing the coating disbonded thickness, the amplitude of the metal corrosion current density in the crevice was significantly greater than the other two kinds; that meant larger aperture space was suitable for the growth and reproduction of SRB, improving the activity of SRB in the crevice, thus greatly accelerating the corrosion rate of metal in the crevice. As shown in Figure 8, when the fungicide was added to the simulated SRB solution, the amplitude of the metal corrosion current density in the initial experiment 
TABLE 4: The electrochemical parameters.

\begin{tabular}{|c|c|c|c|c|c|c|}
\hline $\begin{array}{l}\text { Simulated } \\
\text { solution }\end{array}$ & $\begin{array}{l}\text { Experiment } \\
\text { time }\end{array}$ & $\begin{array}{c}\text { Stripping } \\
\text { depths/mm }\end{array}$ & $\begin{array}{c}\text { Disbonded } \\
\text { thickness } \\
(\mathrm{mm})\end{array}$ & $\begin{array}{c}\text { The corrosion current } \\
\text { density } / \mu \mathrm{A} / \mathrm{cm}^{2}\end{array}$ & $\begin{array}{c}\text { The self-corrosion } \\
\text { potential/mV }\end{array}$ & $\begin{array}{c}\text { The ratio of anode Tafel } \\
\text { slope and cathode Tafel } \\
\text { slope }\end{array}$ \\
\hline \multirow{18}{*}{$\begin{array}{l}\text { Soil } \\
\text { simulated } \\
\text { solution }\end{array}$} & \multirow{6}{*}{$1 \mathrm{~d}$} & \multirow{2}{*}{0} & 0.5 & 23.1029 & -702 & 1.7328 \\
\hline & & & 1.0 & 35.1429 & -719 & 1.6204 \\
\hline & & \multirow{2}{*}{80} & 0.5 & 19.2514 & -722 & 1.6538 \\
\hline & & & 1.0 & 35.3486 & -724 & 1.7384 \\
\hline & & \multirow{2}{*}{160} & 0.5 & 11.5943 & -718 & 1.5963 \\
\hline & & & 1.0 & 34.3171 & -718 & 1.5686 \\
\hline & \multirow{6}{*}{$7 \mathrm{~d}$} & \multirow{2}{*}{0} & 0.5 & 43.7829 & -708 & 1.5726 \\
\hline & & & 1.0 & 38.2800 & -719 & 1.4733 \\
\hline & & \multirow{2}{*}{80} & 0.5 & 30.3086 & -722 & 1.5250 \\
\hline & & & 1.0 & 38.1543 & -717 & 1.3973 \\
\hline & & \multirow{2}{*}{160} & 0.5 & 26.0457 & -725 & 1.4844 \\
\hline & & & 1.0 & 36.8343 & -716 & 1.3790 \\
\hline & \multirow{6}{*}{$14 \mathrm{~d}$} & \multirow{2}{*}{0} & 0.5 & 45.2457 & -701 & 1.4111 \\
\hline & & & 1.0 & 45.8971 & -718 & 1.4050 \\
\hline & & \multirow{2}{*}{80} & 0.5 & 32.3429 & -717 & 1.4049 \\
\hline & & & 1.0 & 48.0971 & -720 & 1.3542 \\
\hline & & \multirow{2}{*}{160} & 0.5 & 27.7543 & -723 & 1.4831 \\
\hline & & & 1.0 & 46.9549 & -713 & 1.3135 \\
\hline \multirow{18}{*}{$\begin{array}{l}\text { Soil } \\
\text { simulated } \\
\text { solution }+ \\
\text { SRB }\end{array}$} & \multirow{6}{*}{$1 d$} & \multirow{2}{*}{0} & 0.5 & 25.8171 & -688 & 1.8134 \\
\hline & & & 1.0 & 35.6800 & -707 & 1.8220 \\
\hline & & \multirow{2}{*}{80} & 0.5 & 20.2457 & -696 & 1.6897 \\
\hline & & & 1.0 & 31.9029 & -710 & 1.6832 \\
\hline & & \multirow{2}{*}{160} & 0.5 & 19.5143 & -700 & 1.6727 \\
\hline & & & 1.0 & 31.7543 & -705 & 1.6649 \\
\hline & & 0 & 0.5 & 30.9143 & -688 & 1.7509 \\
\hline & & 0 & 1.0 & 66.9429 & -692 & 1.7047 \\
\hline & $7 \mathrm{~d}$ & 80 & 0.5 & 28.4971 & -692 & 1.7250 \\
\hline & $7 \mathrm{a}$ & 80 & 1.0 & 67.3714 & -706 & 1.6529 \\
\hline & & 160 & 0.5 & 21.7143 & -695 & 1.6395 \\
\hline & & 100 & 1.0 & 65.6229 & -701 & 1.5372 \\
\hline & & 0 & 0.5 & 78.5143 & -675 & 1.7515 \\
\hline & & 0 & 1.0 & 100.4343 & -692 & 1.5221 \\
\hline & $14 \mathrm{~d}$ & 80 & 0.5 & 87.6457 & -680 & 1.2216 \\
\hline & $14 \mathrm{~d}$ & 80 & 1.0 & 96.6857 & -710 & 1.4924 \\
\hline & & 160 & 0.5 & 95.4914 & -676 & 1.0870 \\
\hline & & & 1.0 & 98.8457 & -701 & 1.4101 \\
\hline & & 0 & 0.5 & 16.3886 & -694 & 1.9859 \\
\hline & & 0 & 1.0 & 33.6514 & -708 & 1.9256 \\
\hline & $1 d$ & 80 & 0.5 & 19.0400 & -692 & 1.4779 \\
\hline & $1 \mathrm{~d}$ & 80 & 1.0 & 34.5714 & -719 & 1.5530 \\
\hline & & 160 & 0.5 & 21.2457 & -696 & 1.3274 \\
\hline & & 100 & 1.0 & 32.9943 & -713 & 1.6431 \\
\hline & & 0 & 0.5 & 33.4433 & -698 & 1.6243 \\
\hline simulated & & 0 & 1.0 & 54.1429 & -695 & 1.7249 \\
\hline solution + & $7 \mathrm{~d}$ & 80 & 0.5 & 43.1143 & -732 & 1.4063 \\
\hline $\mathrm{SRB}+$ & 10 & ou & 1.0 & 51.7086 & -703 & 1.7372 \\
\hline fungicide & & 160 & 0.5 & 47.4286 & -691 & 1.4588 \\
\hline & & 100 & 1.0 & 50.7714 & -696 & 1.5878 \\
\hline & & 0 & 0.5 & 48.6114 & -684 & 1.4157 \\
\hline & & 0 & 1.0 & 79.0457 & -690 & 1.6985 \\
\hline & $14 \mathrm{~d}$ & 80 & 0.5 & 63.8800 & -689 & 1.4475 \\
\hline & $14 \mathrm{U}$ & 80 & 1.0 & 77.1771 & -712 & 1.4383 \\
\hline & & 160 & 0.5 & 75.1714 & -684 & 1.4206 \\
\hline & & 100 & 1.0 & 78.0971 & -700 & 1.4900 \\
\hline
\end{tabular}




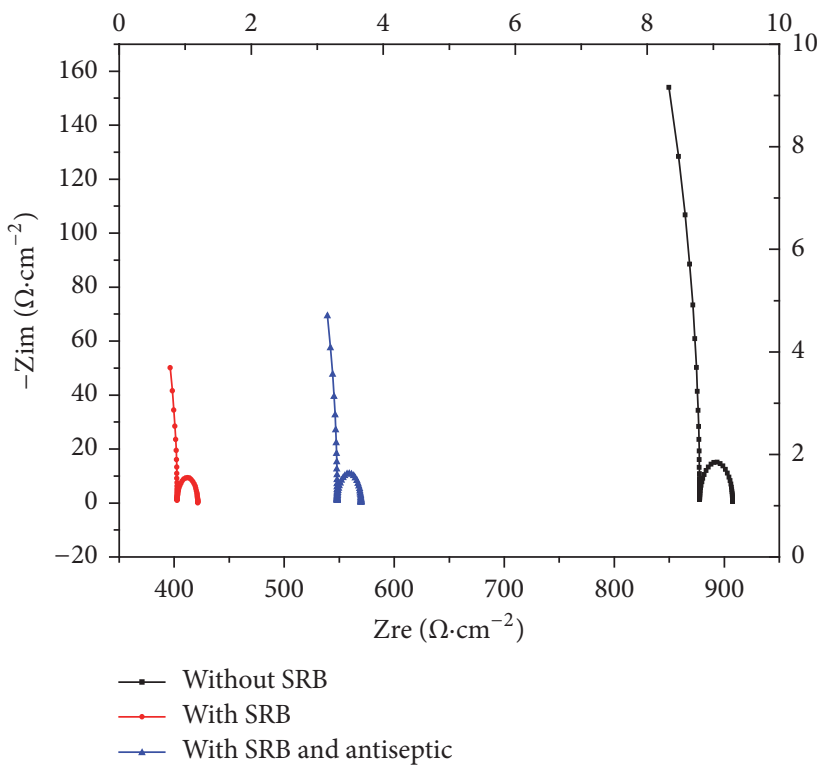

(a) The EIS of the damaged point

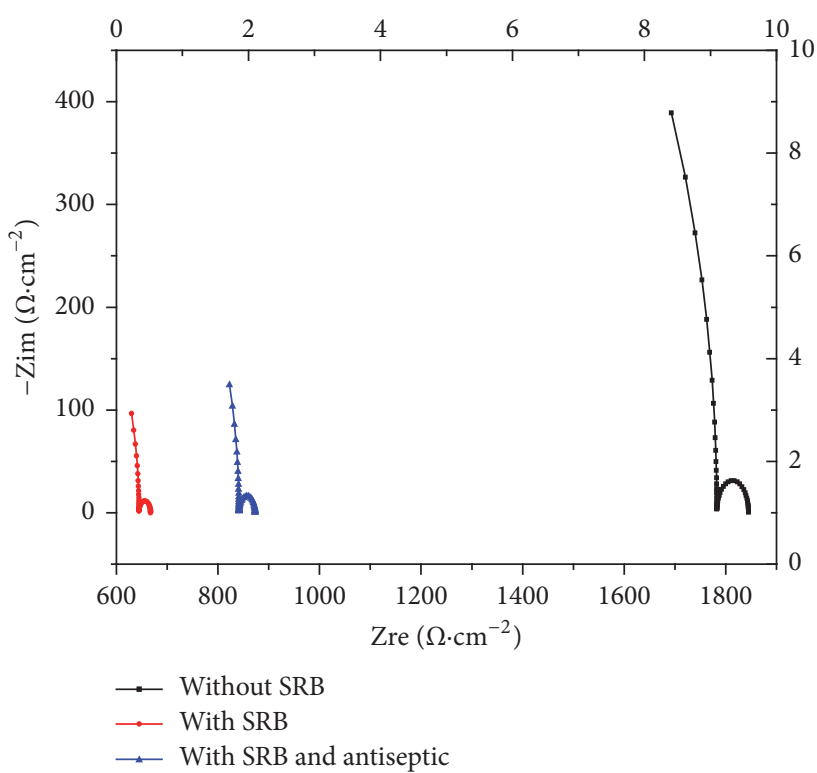

(b) The EIS of the point in the $80 \mathrm{~mm}$ stripping depth

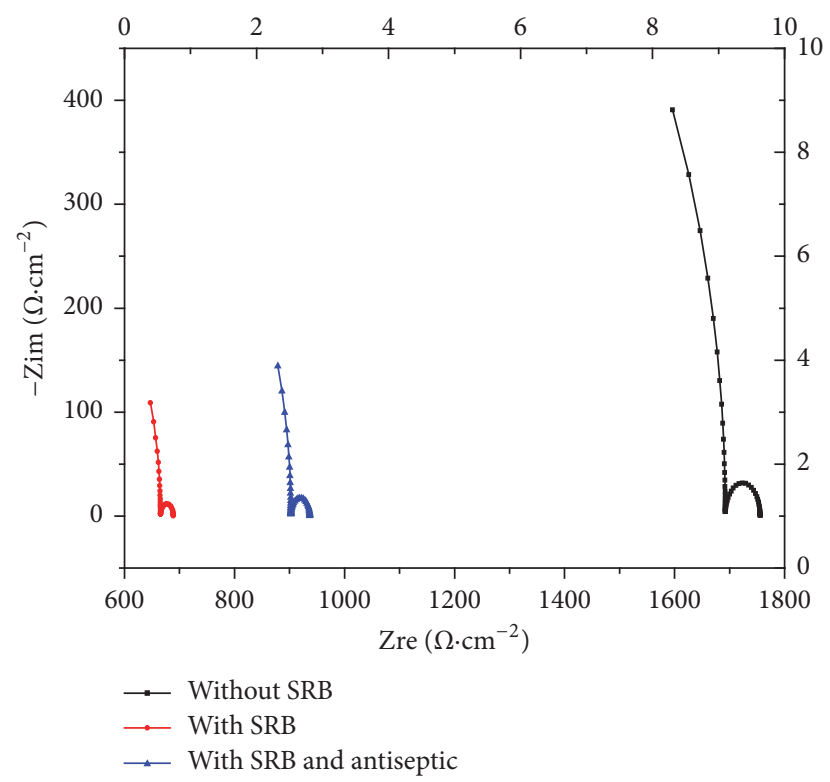

(c) The EIS of the point in the $160 \mathrm{~mm}$ stripping depth

FIGURE 4: The EIS of the base metal under stripping coating in the seventh experiment day.

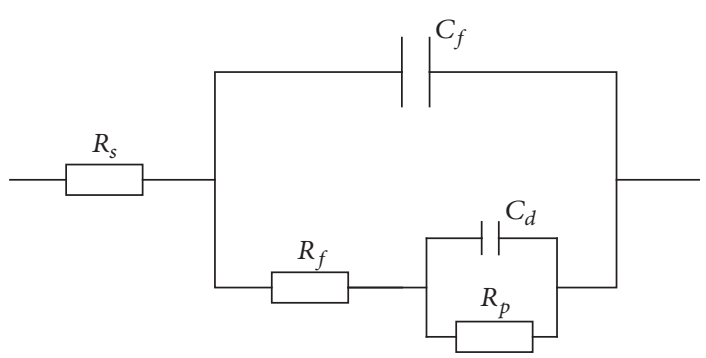

FIGURE 5: The equivalent circuit diagram. 


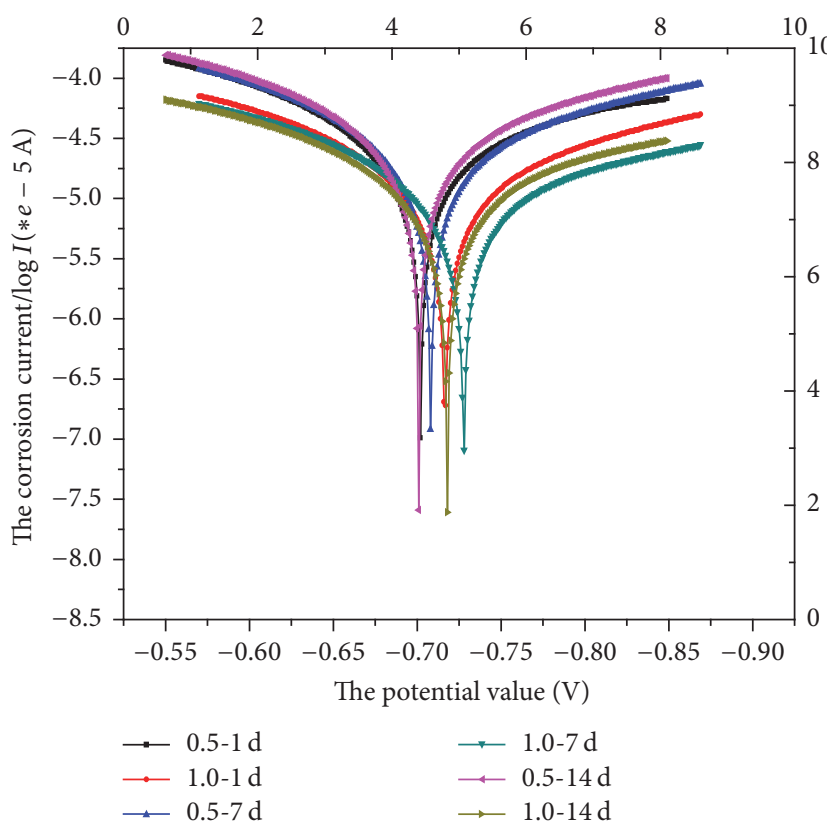

(a) The polarization curves of the damaged point in different time

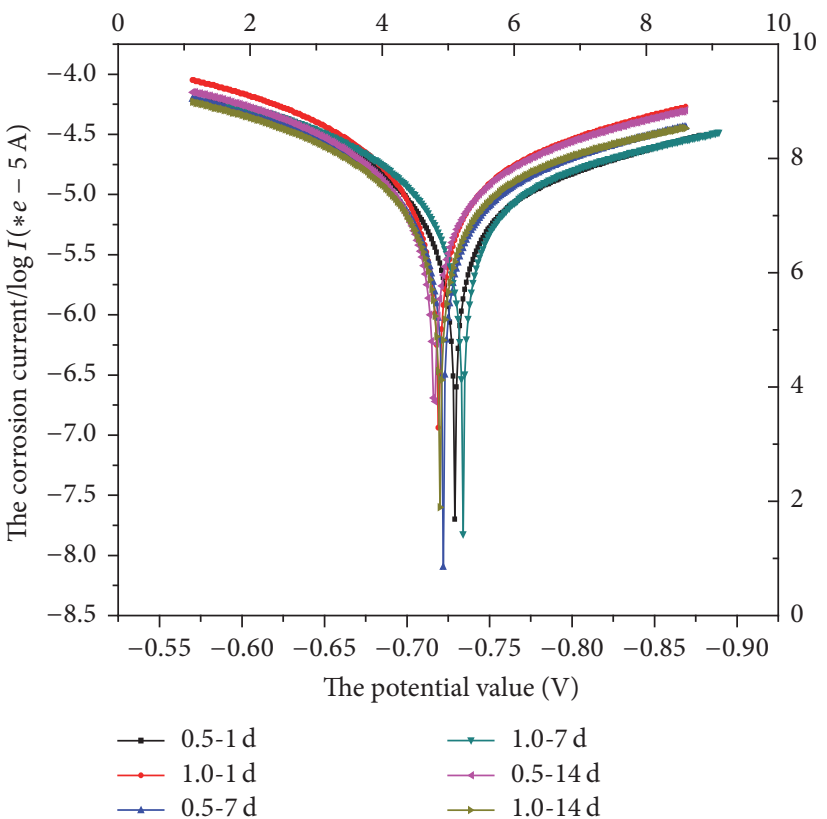

(b) The polarization curves of the point in the $80 \mathrm{~mm}$ stripping depth

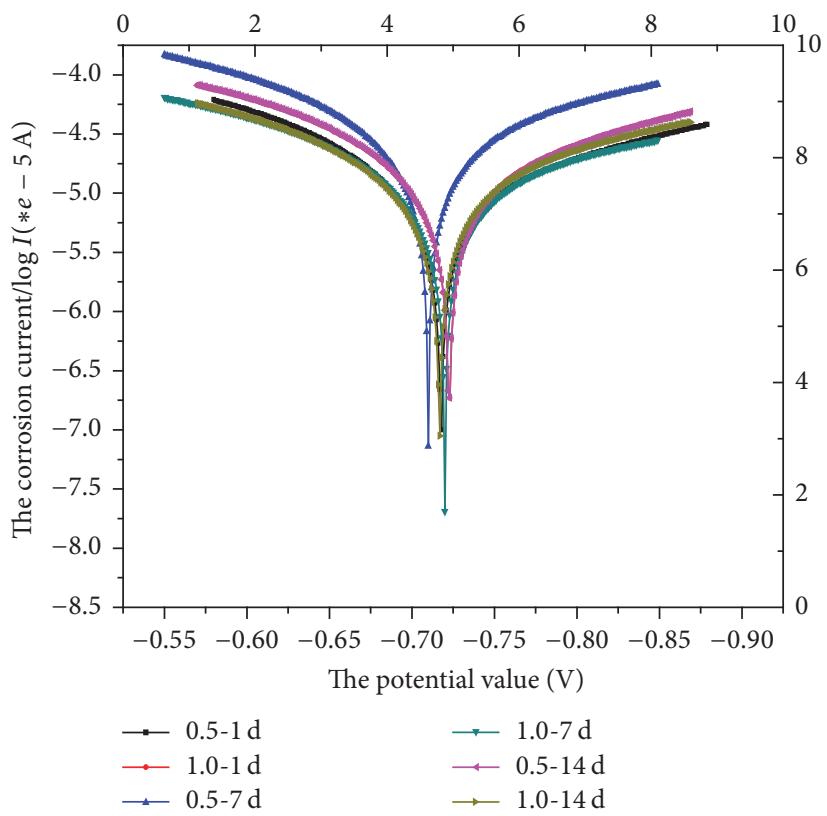

(c) The polarization curves of the point in the $160 \mathrm{~mm}$ stripping depth

FIGURE 6: The polarization curves of various points of the metal substrate in the disbonded crevice under different disbonded thickness in the simulated solution without SRB.

stage was significantly higher than that in the later stage of corrosion with the increase of the coating disbonded thickness. In addition, the ratio of anode Tafel slope and cathode Tafel slope was still more than 1 after increasing the coating disbonded thickness in these three kinds of simulated solution, so the control factor of the corrosion was anode control, but as the coating disbonded thickness increases this ratio had a decreasing trend with and without SRB. The anode control trend was gradually weakened, but this ratio had an increasing trend in the solution environment with SRB and added fungicide, and the anode control trend was gradually enhanced.

The EIS used the ZSimpWin software for fitting. The electrochemical equivalent circuit C (CR (CR)) was composed of a resistance $R$ and a capacitance $C$ to represent the electrode process, the equivalent circuit diagram was the same as Figure 5, and there was no longer a detailed introduction.

As shown in Figure 9, when the stripping depth was $80 \mathrm{~mm}$, the capacitance arc radius of the disbonded thickness of $0.5 \mathrm{~mm}$ was bigger than that of $1.0 \mathrm{~mm}$ in the three kinds of 


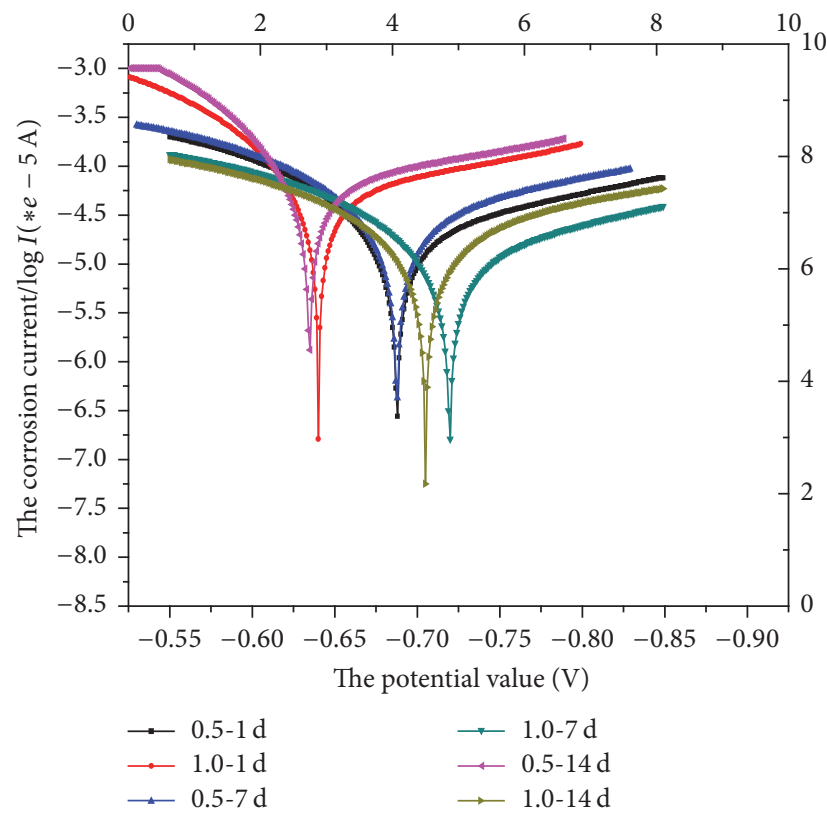

(a) The polarization curves of the damaged point in different time

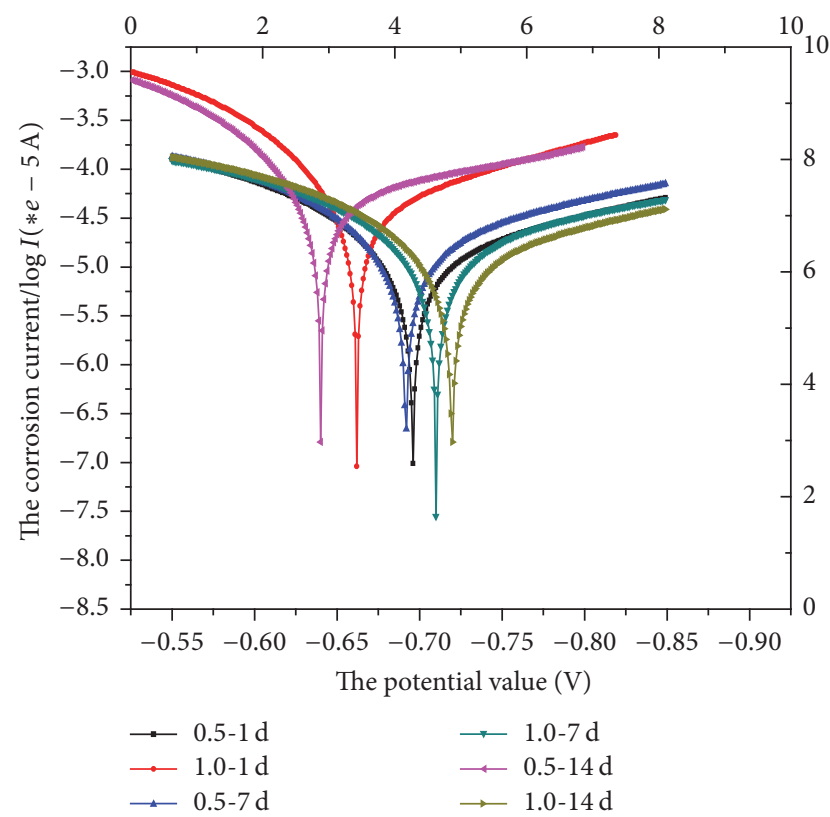

(b) The polarization curves of the point in the $80 \mathrm{~mm}$ stripping depth

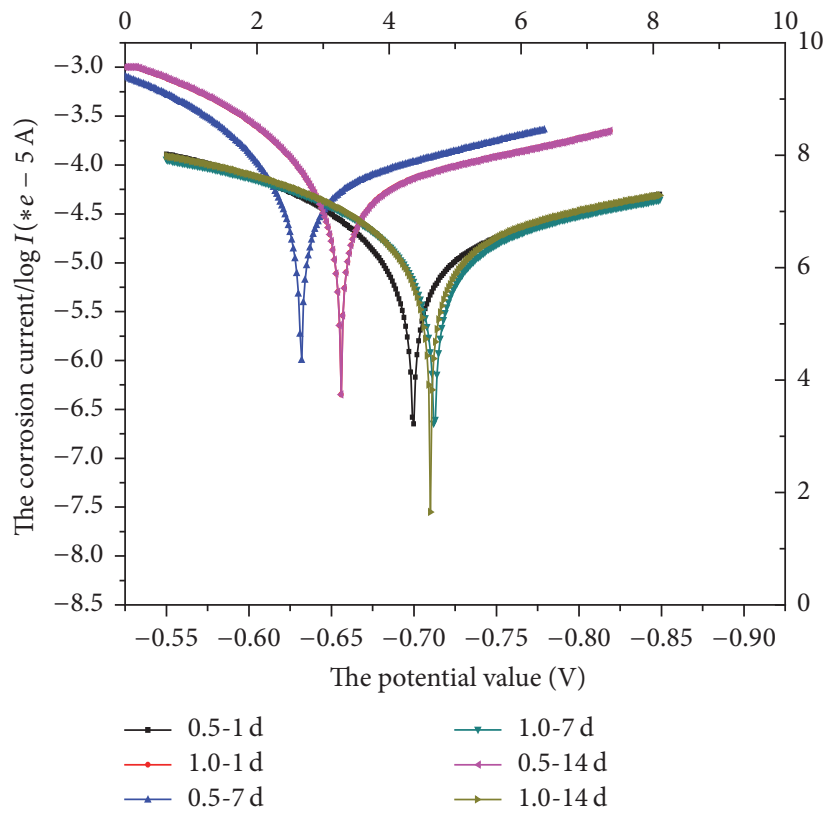

(c) The polarization curves of the point in the $160 \mathrm{~mm}$ stripping depth

FIGURE 7: The polarization curves of various points of the metal substrate in the disbonded crevice under different disbonded thickness in the simulated solution with SRB.

simulated solution in the seventh day. That meant the corrosion resistance of the metal in the crevice with the disbonded thickness $1.0 \mathrm{~mm}$ was worse; the corrosion was more serious. In addition, according to the polarization resistance of the metal in Table 5, we could see that the polarization resistance of the metal in the crevice at the thickness of $0.5 \mathrm{~mm}$ was bigger than that of $1.0 \mathrm{~mm}$ in these three kinds of simulated solution, and the difference of the polarization resistance of the metal in the solution with SRB was the maximum. Therefore, increasing the coating disbonded thickness would enhance the resistance of the metal corrosion process, and it also could accelerate the corrosion rate of the metal in the disbonded crevice. The change of the coating disbonded thickness had a far greater impact on the corrosion rate of the metal in the simulated solution with SRB. The results above were consistent with the conclusions obtained by the method of polarization curve analysis.

\section{Conclusion}

(1) Whether the simulated solution is without or with SRB, the self-corrosion potential of the metal in the crevice under 


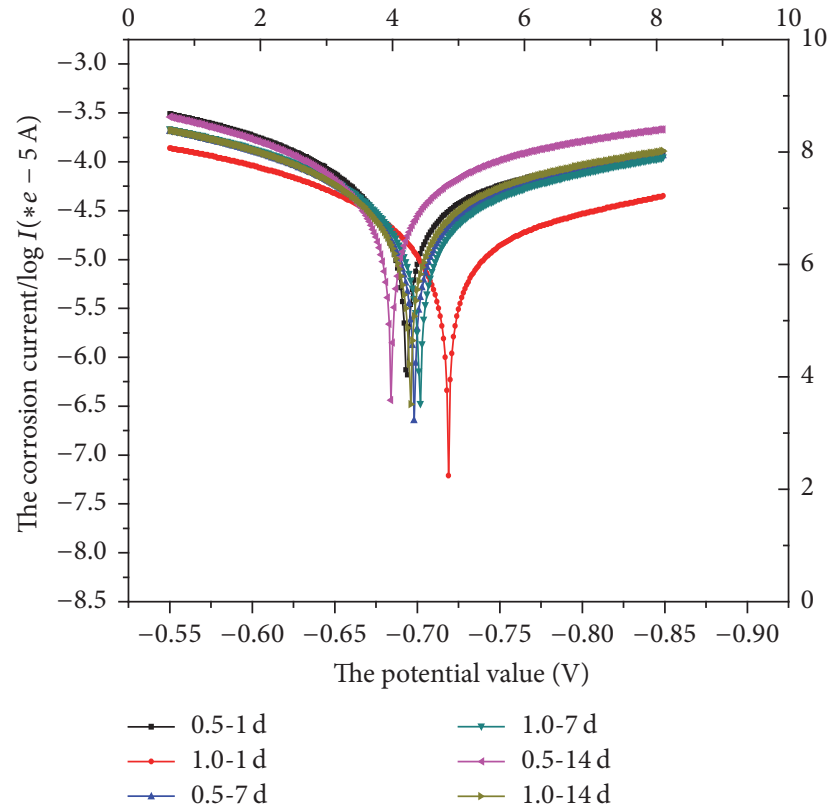

(a) The polarization curves of the damaged point in different time

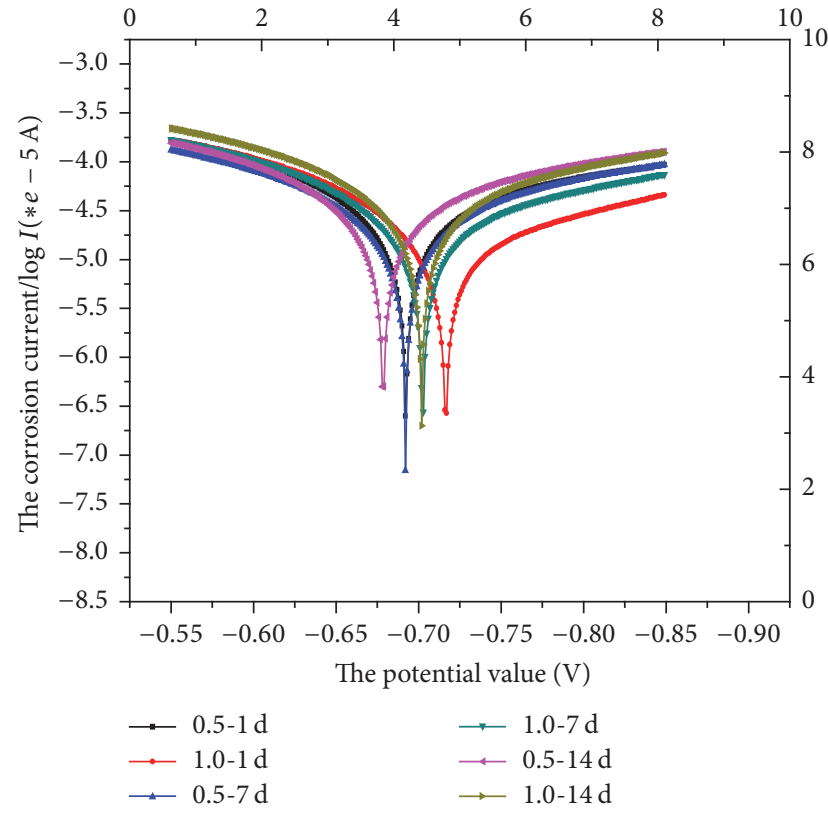

(b) The polarization curves of the point in the $80 \mathrm{~mm}$ stripping depth

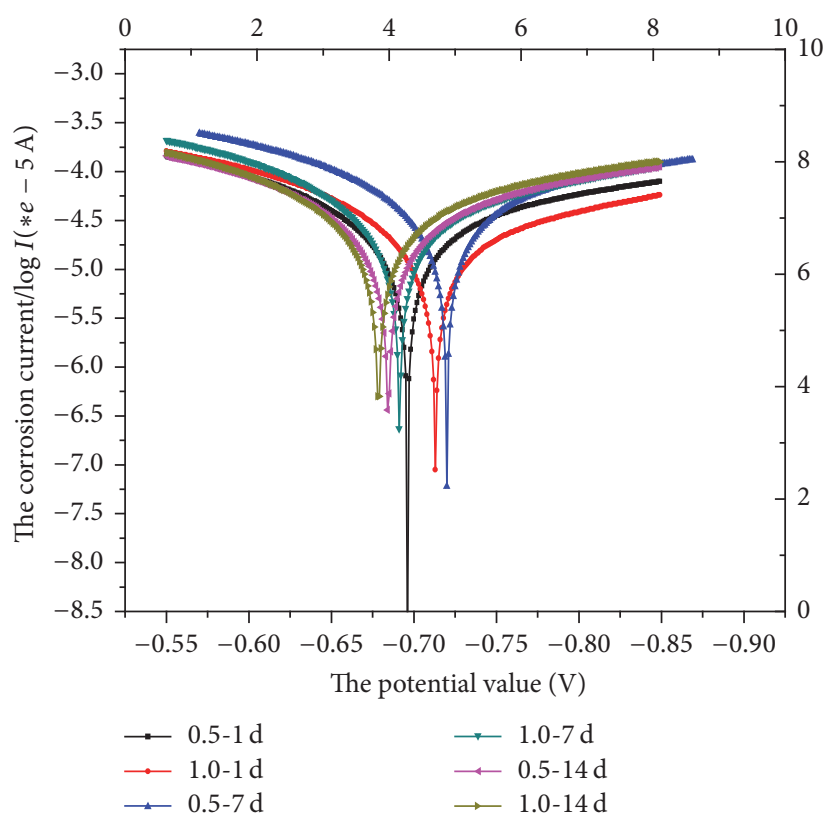

(c) The polarization curves of the point in the $160 \mathrm{~mm}$ stripping depth

FIGURE 8: The polarization curves of various points of the metal substrate in the disbonded crevice under different disbonded thickness in the simulated solution with SRB and fungicide.

TABLE 5: The polarization resistance of the metal at the distance of $80 \mathrm{~mm}$ under different disbonded thickness $/ \Omega$.

\begin{tabular}{|c|c|c|c|c|}
\hline $\begin{array}{l}\text { The disbonded } \\
\text { distance } / \mathrm{mm}\end{array}$ & The experiment time & The simulated solution & $\begin{array}{l}\text { The disbonded } \\
\text { thickness/mm }\end{array}$ & $R_{p} / \Omega$ \\
\hline \multirow{6}{*}{80} & \multirow{6}{*}{$7 \mathrm{~d}$} & \multirow{2}{*}{ Soil simulated solution } & 0.5 & 3246.3 \\
\hline & & & 1.0 & 3090.4 \\
\hline & & \multirow{2}{*}{ Soil simulated solution + SRB } & 0.5 & 1632.7 \\
\hline & & & 1.0 & 1152.4 \\
\hline & & \multirow{2}{*}{ Soil simulated solution + SRB + fungicide } & 0.5 & 1321.2 \\
\hline & & & 1.0 & 1290.7 \\
\hline
\end{tabular}




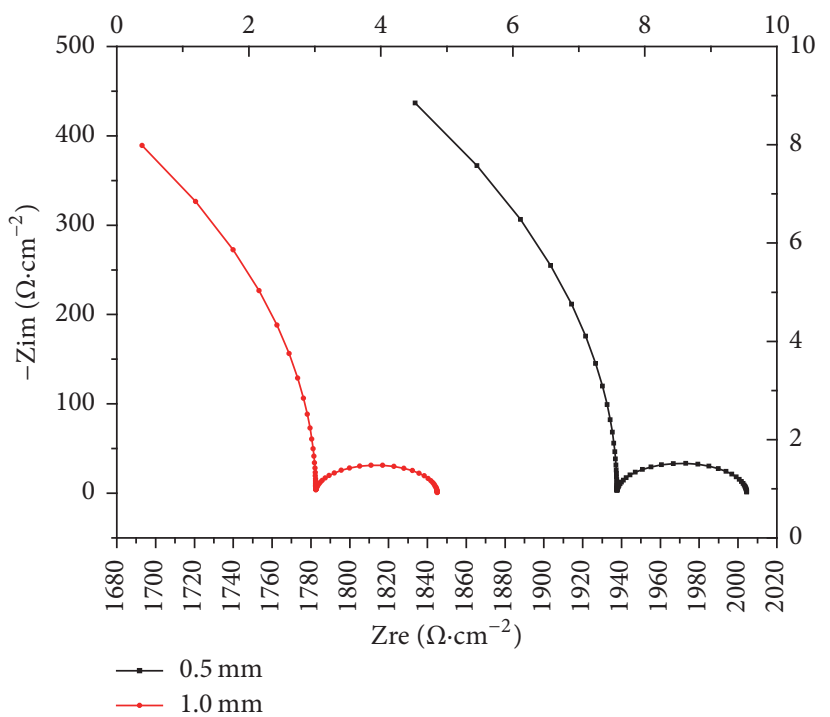

(a) The EIS of the solution without SRB

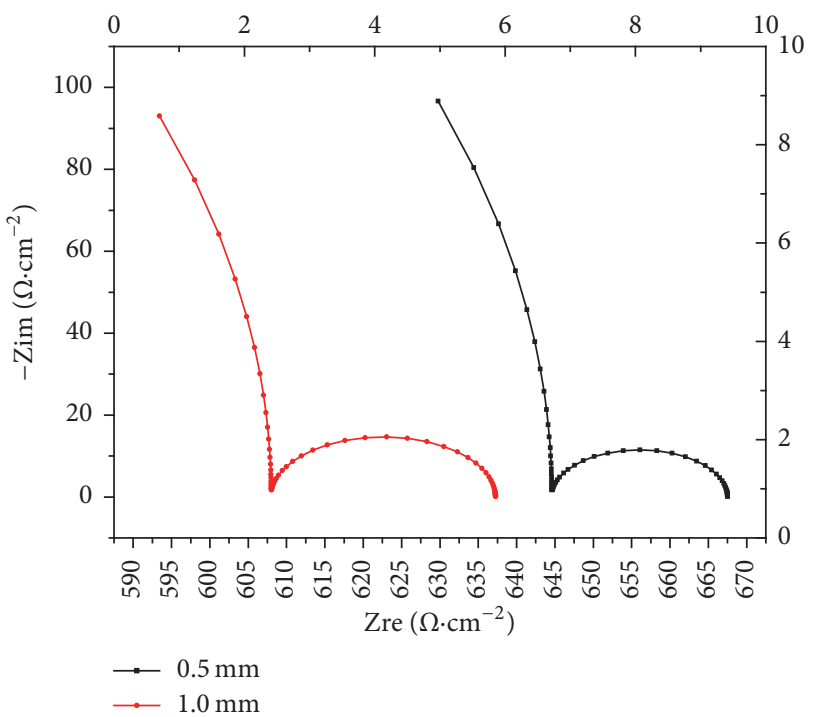

(b) The EIS of the solution with SRB

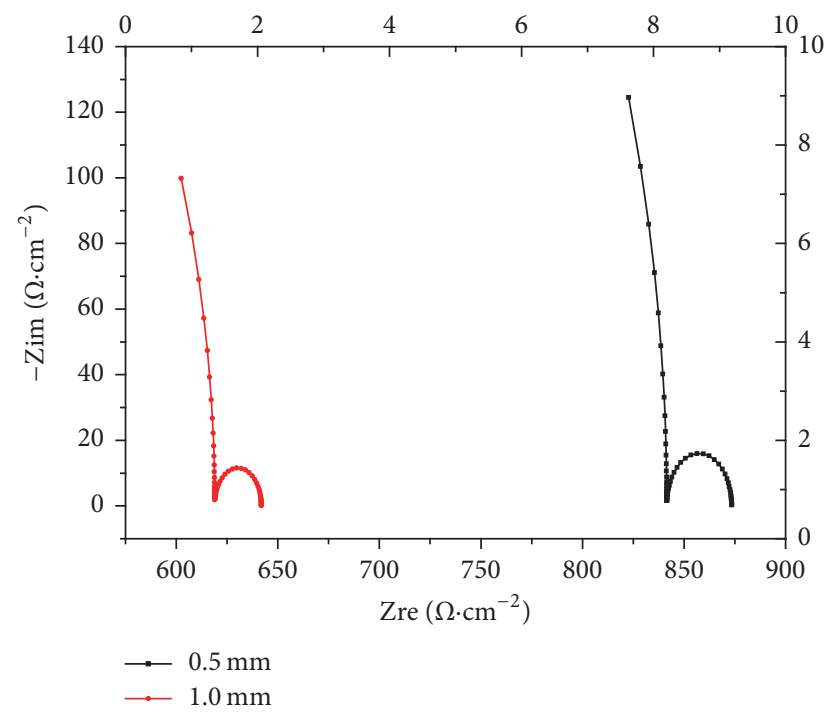

(c) The EIS of the solution with SRB and adding the fungicide

FIGURE 9: The EIS of the metal at the distance of $80 \mathrm{~mm}$ under different disbonded thickness in the seventh experiment day.

the same disbonded distance had little change in the initial experiment stage. In the later stage, the self-corrosion potential of the metal in the crevice had amplitude obviously, and the amplitude in the SRB solution environment was greater than that without SRB. With the extension of the experiment time, whether the solution is without or with SRB, the corrosion current density of the metal in the crevice under the same disbonded distance increased gradually, and the corrosion current density of the metal in the crevice in the simulated solution with SRB was significantly greater than that without SRB; that meant SRB could accelerate the corrosion of the metal in the disbonded crevice.

(2) In the SRB solution where the fungicide was added at the same time, the self-corrosion potential of the metal in the disbonded crevice did not change much, but the corrosion current density significantly decreased; that meant the growth and reproduction of SRB were inhibited after adding the fungicide, so as to slow down the corrosion rate of the metal in the crevice. With the experiment time extension, the self-corrosion potential of the metal in the crevice shifted negatively before moving to positive direction at the same depths, but the corrosion current density was increasing. When the experimental time was the same, with the increase of the coating disbonded depths, the self-corrosion potential of the metal in the crevice did not change much, but the corrosion current density increased.

(3) In the three kinds of simulated solution, with the increase of the coating disbonded thickness, the self-corrosion potential of the metal in the disbonded crevice shifted negatively, and the corrosion current density increased significantly. It indicated that increasing the coating disbonded thickness could accelerate the corrosion of the metal in the 
crevice, and in the simulated solution with SRB, the amplitude of the corrosion current density of the metal in the crevice was greater than that in other two kinds of solution.

\section{Conflicts of Interest}

The authors declare that there are no conflicts of interest regarding the publication of this article.

\section{Acknowledgments}

The research work was supported by the Central College Foundation of CAUC (3122017038), the Opening Project of Guangxi Colleges and Universities Key Laboratory of Beibu Gulf Oil and Natural Gas Resource Effective Utilization (2016KLOG21), and the National Science Foundation (U1633111).

\section{References}

[1] I. U. L. Xu and W. Xiaoyu, "The research of oil and gas pipeline corrosion and protection technology," in Advances in Petroleum Exploration and Development, vol. 7, pp. 102-105, 2014.

[2] D. B. Yadav, K. S. Jha, and R. Kumar, "Pipeline Corrosion in a 24" dia Crude Oil Pipeline due to Interference from High Voltage AC Transmission Line: A Case Study," in Proceedings of the 10th Pipeline Technology Conference 2015, EITEP Institute, 2015.

[3] G. Cui, Z.-L. Li, C. Yang, and M. Wang, "The influence of DC stray current on pipeline corrosion," Petroleum Science, vol. 13, no. 1, pp. 135-145, 2016.

[4] Y. Liu, B. Zhang, Y. Zhang, L. Ma, and P. Yang, "Electrochemical polarization study on crude oil pipeline corrosion by the produced water with high salinity," Engineering Failure Analysis, vol. 60, pp. 307-315, 2016.

[5] H. Tian and Y. Frank Cheng, "Novel inhibitors containing multi-functional groups for pipeline corrosion inhibition in oilfield formation water," Corrosion, vol. 72, no. 4, pp. 472-485, 2016.

[6] S. Lyon, R. Bingham, and D. Mills, "Advances in corrosion protection by organic coatings: what we know and what we would like to know," Progress in Organic Coatings, vol. 102, pp. 2-7, 2017.

[7] B. T. Richards, M. R. Begley, and H. N. G. Wadley, "Mechanisms of ytterbium monosilicate/mullite/silicon coating failure during thermal cycling in water vapor," Journal of the American Ceramic Society, vol. 98, no. 12, pp. 4066-4075, 2015.

[8] A. A. Vereschaka, B. Y. Mokritskii, N. N. Sitnikov, G. V. Oganyan, and A. Y. Aksenenko, "Study of mechanism of failure and wear of multi-layered composite nano-structured coating based on system Ti-TiN-(ZrNbTi)N deposited on carbide substrates," Journal of Nano Research, vol. 45, pp. 110-123, 2017.

[9] F. Varela, M. Forsyth, and M. Y. J. Tan, "Electrochemically monitoring localized corrosion patterns and CP effectiveness under disbonded coatings," NACE - International Corrosion Conference Series, vol. 2015-, 2015.

[10] Y. A. N. Maocheng, X. U. Jin, Y. U. Libao, W. U. Tangqing, S. U. N. Cheng, and K. E. Wei, "EIS analysis on stress corrosion initiation of pipeline steel under disbonded coating in near-neutral pH simulated soil electrolyte," Corrosion Science, vol. 110, pp. 23-34, 2016.

[11] Y. Chen, "Electrochemical impedance spectroscopy study for cathodic disbonding test technology on three layer polyethylene anticorrosive coating under full immersion and alternating dry-wet environments," International Journal of Electrochemical Science, pp. 10884-10894, 2016.

[12] D. Xu, Y. Li, and T. Gu, "Mechanistic modeling of biocorrosion caused by biofilms of sulfate reducing bacteria and acid producing bacteria," Bioelectrochemistry, vol. 110, pp. 52-58, 2016.

[13] D. Xu and T. Gu, "Carbon source starvation triggered more aggressive corrosion against carbon steel by the Desulfovibrio vulgaris biofilm," International Biodeterioration and Biodegradation, vol. 91, pp. 74-81, 2014.

[14] D. Xu, Y. Li, F. Song, and T. Gu, "Laboratory investigation of microbiologically influenced corrosion of C1018 carbon steel by nitrate reducing bacterium Bacillus licheniformis," Corrosion Science, vol. 77, pp. 385-390, 2013.

[15] H. Venzlaff, D. Enning, J. Srinivasan et al., "Accelerated cathodic reaction in microbial corrosion of iron due to direct electron uptake by sulfate-reducing bacteria," Corrosion Science, vol. 66, pp. 88-96, 2013.

[16] D. Enning and J. Garrelfs, "Corrosion of iron by sulfatereducing bacteria: New views of an old problem," Applied and Environmental Microbiology, vol. 80, no. 4, pp. 1226-1236, 2014.

[17] S. Chen, P. Wang, and D. Zhang, "Corrosion behavior of copper under biofilm of sulfate-reducing bacteria," Corrosion Science, vol. 87, pp. 407-415, 2014.

[18] M. G. Chesnokova, V. V. Shalaj, Y. A. Kraus et al., "Analysis of corrosion defects on oil pipeline surface using scanning electron microscopy and soil thionic and sulfate-reducing bacteria quantification," Procedia Engineering, vol. 152, pp. 247-250, 2016.

[19] W. Wang, Q. Wang, C. Wang, and J. Yi, "Experimental studies of crevice corrosion for buried pipeline with disbonded coatings under cathodic protection," Journal of Loss Prevention in the Process Industries, vol. 29, no. 1, pp. 163-169, 2014.

[20] F. N. Varela, M. Y. Tan, and M. Forsyth, "A novel approach for monitoring pipeline corrosion under disbonded coatings," in Proceedings of the 2014 10th International Pipeline Conference, p. V002T06A068, Calgary, Alberta, Canada. 

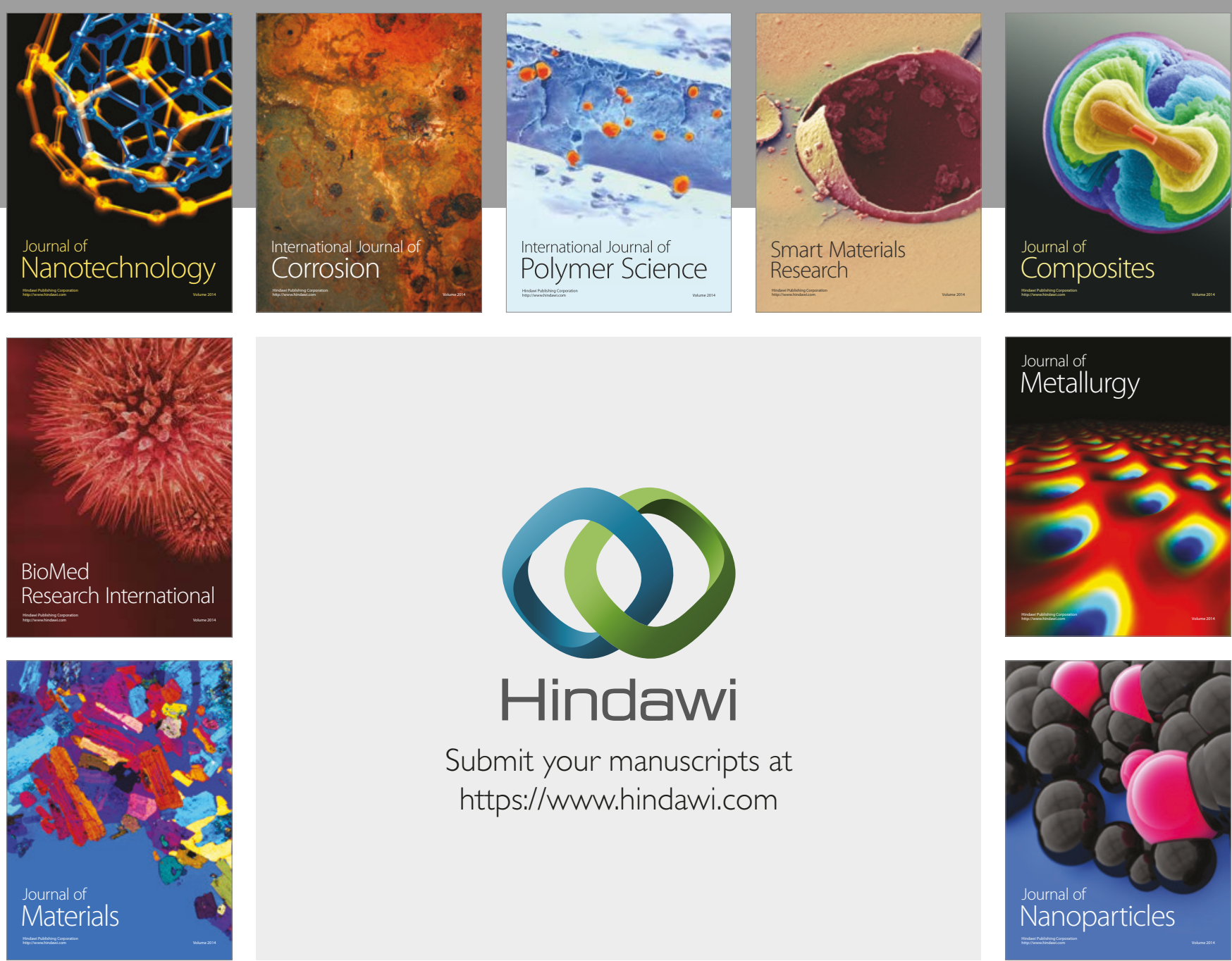

\section{Hindawi}

Submit your manuscripts at

https://www.hindawi.com
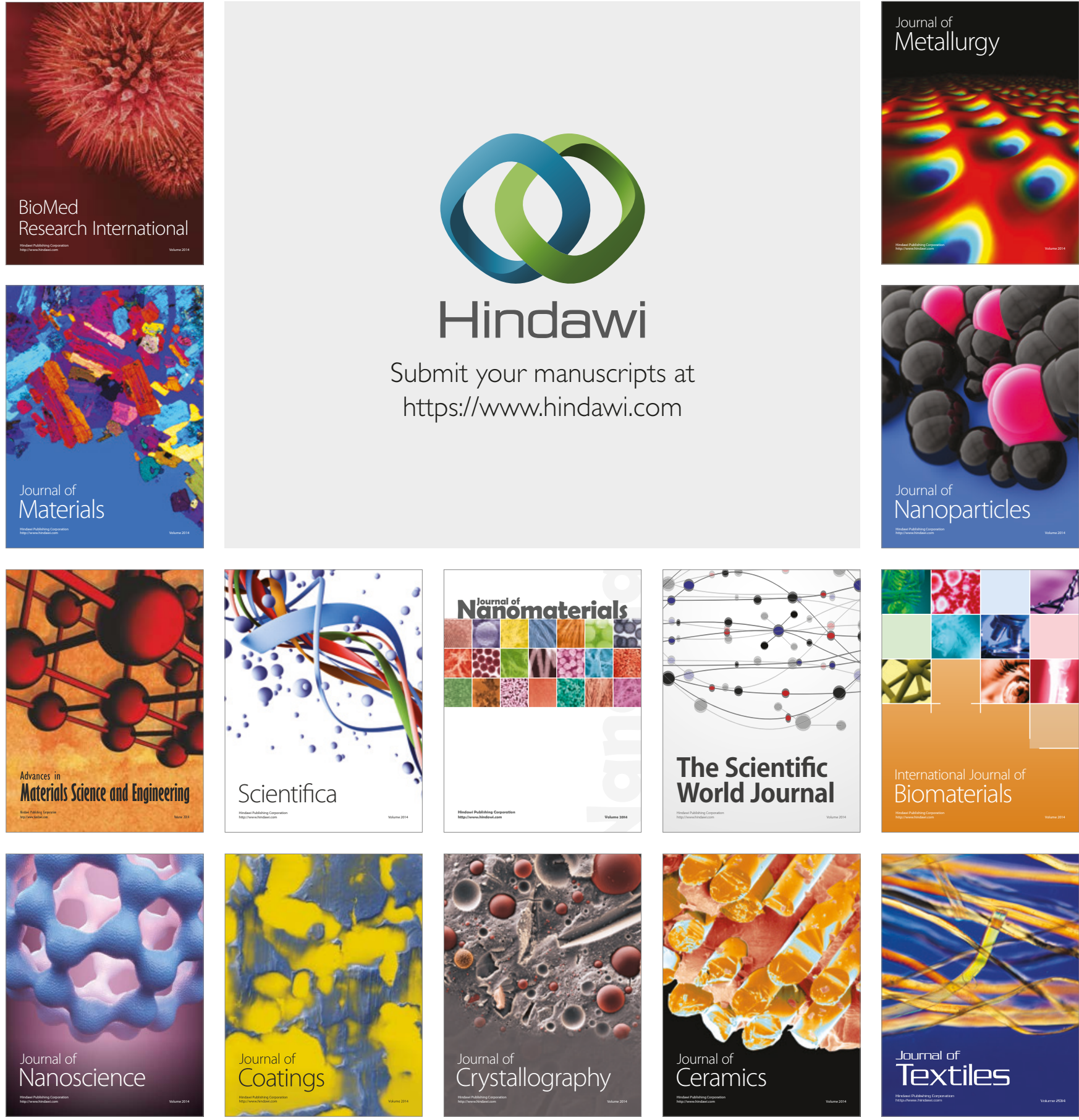

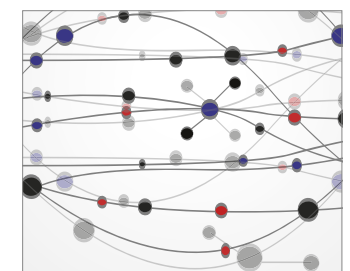

The Scientific World Journal
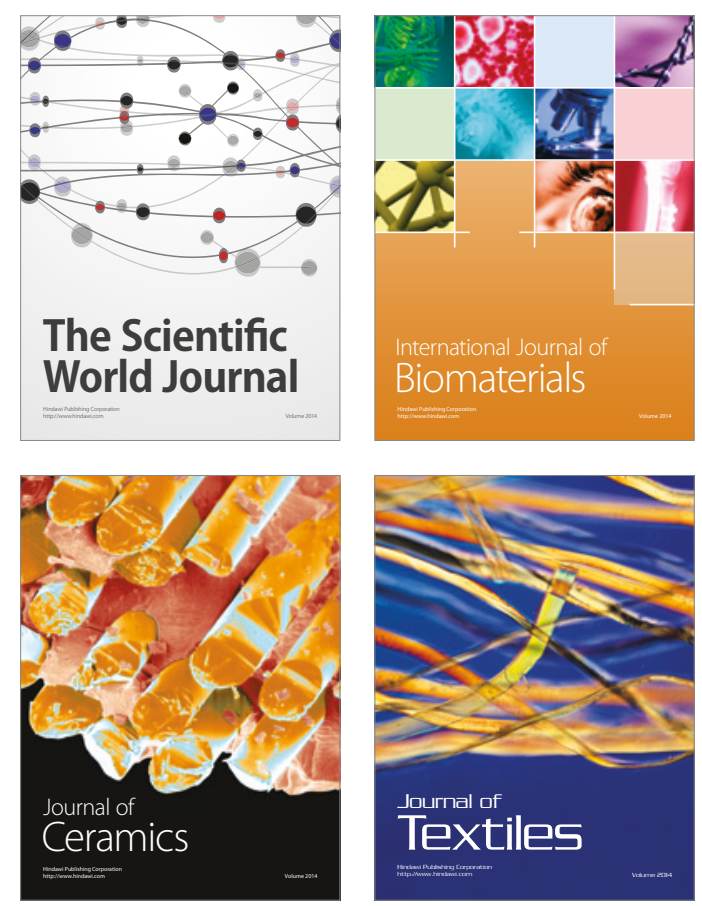